\title{
What Determines Chinese Stock Returns?
}

\author{
Fenghua Wang and Yexiao $\mathrm{Xu}^{*}$
}

\begin{abstract}
Size, not book-to-market, helps to explain cross-sectional differences in Chinese stock returns from 1996-2002. Similar to the U.S. experience, beta does not account for return differences among individual stocks. Due to the speculative nature of the Chinese capital markets and low quality in the accounting information, these results suggest that the book-tomarket variable may have reflected fundamentals in the U.S. markets. Due to the unique nature of the traded Chinese companies, we have proposed using a floating ratio as a proxy for fundamentals. Floating ratio reflects the expected corporate governance in China, which help to predict a firm's future cash flow. Not only the cross-sectional evidence highly supports our prediction for the floating ratio variable, a three-factor model which includes size and ratio proxies has significantly increased the explanatory power of a market model from $81 \%$ to $90 \%$.
\end{abstract}

\footnotetext{
* Research Center, Shanghai Stock Exchange, 86-21-6880-4230, fhwang@sse.com.cn and School of Management, University of Texas at Dallas, 972-883-6703, yexiaoxu@utdallas.edu, respectively. We acknowledge financial support from Shanghai Stock Exchange. Address correspondence to Yexiao Xu, SM31, School of Management, University of Texas at Dallas, Richardson, Texas 75083.
} 


\title{
What Determines Chinese Stock Returns?
}

\begin{abstract}
Size, not book-to-market, helps to explain cross-sectional differences in Chinese stock returns from 1996-2002. Similar to the U.S. experience, beta does not account for return differences among individual stocks. Due to the speculative nature of the Chinese capital markets and low quality in the accounting information, these results suggest that the book-tomarket variable may have reflected fundamentals in the U.S. markets. Due to the unique nature of the traded Chinese companies, we have proposed using a floating ratio as a proxy for fundamentals. Floating ratio reflects the expected corporate governance in China, which help to predict a firm's future cash flow. Not only the cross-sectional evidence highly supports our prediction for the floating ratio variable, a three-factor model which includes size and ratio proxies has significantly increased the explanatory power of a market model from $81 \%$ to $90 \%$.
\end{abstract}




\section{Introduction}

Modern finance theory started from Markowitz's (1952) portfolio theory, which predicts how individual investors allocate their assets by balancing the risk and return tradeoffs. Based on this theory, Sharpe (1963), Lintner (1965), and Black (1965) developed the so called Capital Asset Pricing Model (CAPM). For the first time their theory clearly prescribes that it is the individual stocks' co-movements with the overall markets that determine stocks' expected returns (thus the stock prices). In other words, it is the systematic risk that matters in asset pricing. The CAPM has been under intensive scrutiny since its birth. Early empirical studies generally failed to reject the model (see Fama and MacBeth, 1973). In recent years, one of the most influential papers by Fama and French (1992) questioned the cross-sectional predictability of the CAPM. Despite the heated debate, the CAPM still receives wide attention especially from the practitioners. At the same time, for good or bad, we have at least learned that there might be multiple factors in determining the asset returns. If we leave the theoretical interpretation aside for now, Fama and French's (1993) three-factor model, which includes the market factor, the size proxy, and the book-to-market equity proxy, can be considered as the state of art in practice.

The three-factor model has been empirically tested and proved to be useful for most mature equity markets (see for example, Chan, Hamao, and Lakonishok, 1991; Daniel, Titman, and Wei, 2001, etc.). Due to political and culture differences, each capital market embraces different investment environment. Therefore, the price formation process and risk factors might be different. This suggests that it is important to study the robust issue of these factors in an emerging capital market also.

Starting from ground zero in 1990, the Chinese stock market is one of the fastest growing markets of all times. At the end of 2002, the number of listed companies exceeded 1200, and the total market capitalization for tradable shares stood at US\$140 billion ${ }^{1}$, or $12 \%$ of the GDP. When the stock markets were newly established in 1990, there were only A-share stocks available for domestic investors using RMB denomination. These stocks are listed on the mainland Chinese stock exchanges. The B-share markets were introduced in February 1992, which is only available for foreign investors with U.S. dollar denomination. The B-share stocks are also listed on mainland stock exchanges. Historically, the B-share markets were very illiquid with large discounts relative to the A-share markets. The discounts have been reduced

\footnotetext{
${ }^{1}$ Assuming an exchange rate of 1 US $\$=$ RMB8.3 here and afterwards.
} 
substantially after allowing domestic investors to invest in the B-share markets in 2001. Since Bshare markets are much smaller than the A-share markets with less than $10 \%$ of the total number of stocks outstanding, we focus on the A-share markets in this study. ${ }^{2}$

Like many emerging markets, the Chinese market also suffers from unsatisfactory corporate governance, dubious accounting practice, market manipulation, and insider trading problems. Not only there lacks of institutional investors, but most investors have traded speculatively with very short holding periods. With round trip trading costs approaching $1 \%$ of the total transactions, the average annual turnover from 1996 to 2002 exceeded 500\% (see Table $2)$ ! With such a high turnover ratio, investors were interested more in short term gains and ignored long term investment objectives based on future profitability of a firm. Such a unique investment environment provides a natural laboratory to study the asset pricing issue which avoids the data snooping problem. In particular, it is interesting to know whether there is a size effect and how does it compare to those found in mature markets such as the U.S. and Japan. Does the book-to-market variable still explain cross-sectional difference in stock returns? Answers to these questions will not only provide further understanding as to whether these useful factors as evident in the mature markets are related to fundamentals, but also will reveal additional important factors in pricing the Chinese stocks.

There are two unique perspectives that make this study interesting and useful. First, the investment behavior of general investors and the quality of accounting information suggest that information revealed from the "book" may play a less important role than that in mature markets. Currently, public institutional investment, including mutual funds, pension investment, and insurance companies account less than $10 \%$ of the total market capitalization. It is also believed that private investment companies manage less than $30 \%$ of the total outstanding shares. Therefore, majority shares are owned by individuals. Second, about 2/3 of the total market capitalization is currently owned by the state. These shares are prohibited from trading at the exchanges because of the special Chinese ownership structure. Such a unique structure may have affected the risk profiles and future cash flow opportunities of a company. In other words, the price formation process and risk factors might be different for Chinese equities. We argue that the floating ratio can approximate the corporate governance in the Chinese market. As

\footnotetext{
${ }^{2}$ In addition, a few companies have also issued H-shares, which are denominated in Hong Kong dollars and are listed on Hong Kong stock exchanges.
} 
shown in Gompers, et al. (2003) that corporate governance affect firm performance, the floating ratio may serve as a better proxy the fundamental risks in China than the boo-to-market variable. Indeed, we have found supporting evidence.

The paper is organized as the followings. In the next section, we will briefly discuss the characteristics of the Chinese stock markets and the methodologies employed in this study. In Section 3, we will perform cross-sectional tests on both the conventional factors and the proposed factor. The dynamic properties of the three factors, including the market return, the size proxy, and the floating ratio proxy are studied in Section 4. Section 5 provides concluding comments. 


\section{Data and Methodology}

The key issue of this study is the robustness of the Fama and French (1992) factors in pricing equity stocks. Due to the unique Chinese market structure, we also investigate an additional factor that might affect stock returns. Therefore, we have not only used the individual stock return information and accounting information, but also collected some unique information including the floating ratio of a public traded firm.

\subsection{The data source}

We use the 2002 version of the China Stock Market \& Accounting Research (CSMAR) database which includes both trading and financial statement data of all listed Chinese companies since their IPOs. This is the most reliable and thus widely used security database in China. The database starts from the beginning of the Chinese stock market at the end of 1990. As discussed earlier, we focus on the non-financial A-share ${ }^{3}$ stocks due to the size and the liquidity issues of the B-share markets. These stocks are only available to domestic investors and are traded on either Shanghai Stock Exchange or Shenzhen Stock Exchange. The IPO month returns could be problematic since two thirds of the individual stocks have a price jump over 50\% during the IPO month. The price jump is due to the fact that IPO prices were determined by the CSRC (the China Securities Regulatory Commission) according to P/E ratios being set between 15 and 20. Such an IPO P/E ratio is usually much lower than the prevailing market level. Therefore, during the entire sample period, we exclude the first month return data of individual stocks from our study.

Due to changes in accounting procedures and regulations, from 1999 some listed companies began to experience negative book value of equity. We exclude these companies' after their book value turns negative. ${ }^{4} \mathrm{We}$ also exclude a stock from our sample if it ceases trading for more than three months after it has been listed.

\subsection{Summary statistics for A-share stocks}

In order to provide an overall view about the Chinese stock markets and facilitates comparison with other studies, we provide summary statistics for A-share stocks in Table 1.

\footnotetext{
${ }^{3}$ There are only a few financial companies by the end of 2002.

${ }^{4}$ A total of 27 companies have experienced negative book values starting from 1999, they are a very small percentage of all the listed companies.
} 
China established Shanghai and Shenzhen Stock Exchanges at the end of 1990. China Securities Regulatory Commission approves stock listing and decides which stock should be traded on which exchanges. For the first year, there were only eight publicly traded stocks. The total number of stocks in our sample increased to 14 and 53 at the end of year 1991 and 1992, respectively. Since then, we have experienced a rapid increase in the number of traded stocks. By the end of 2002, there were more than 1200 listed companies on the two exchanges as shown in Table 1. At the same time, the average market capitalizations have increased from $\$ 46$ million in 1993 to $\$ 117$ million in 2002 with a peak value of $\$ 176$ million occurred in 2000. Although majority stocks belong to small-cap stocks by the U.S. standard, the speed of growth is very high.

It is also interesting to ask whether such growth in firm size is primarily due to increase in the offer size of new stocks or appreciation in stock prices. As shown in Table 1, most share prices range from a couple of RMB to $20 \mathrm{RMB}$. The average price level has fluctuated greatly in the first three years of our sample period with lowest level occurred in 1995. Since then, the average price level has been around 10 RMB per share except for year 2000. Moreover, from the distribution of individual prices we see that the price variations were also relatively stable and small. This suggests that the cross-sectional explanatory power may simply hinge on the total number of shares outstanding, which makes the size effect, if any, even more puzzling.

\section{Insert Table 1 Approximately Here}

Although there are several indices available, they are lack of representativeness for our study. For example, some indices use total outstanding shares to weight individual stock returns. As argued in Malkiel and $\mathrm{Xu}$ (2001), such practice is inconsistent with the tradition of asset pricing framework. Other indices would assign different weights for different industry. Since we study the pricing issue for the majority stocks traded on both exchanges, we construct a value weighted index in this study. In particular, we use tradable shares to compute the total market capitalization from asset pricing perspective since the shares owned by the state are prohibited from trading at the exchanges ${ }^{5}$. Over the ten-year period from 1993 to 2002, the value-weighted index has returned an arithmetic average monthly return of $2.1 \%$, with a standard deviation of $15.8 \%$ as shown in Table 2. This level of volatility far exceeds that of the U.S. stocks. In

\footnotetext{
${ }^{5}$ The value weighted market index so constructed is used throughout this paper.
} 
contrast, the average monthly volatility has decreased to $9.1 \%$ during the $1996-2002$ sample period despite the fact that the average index return remained the same. This is consistent with Xu's (2003) finding of a decreasing trend in the market volatility. The observed low volatility with the same average return may suggest that the $10 \%$ price limit implemented toward the end of 1996 is effective.

\section{Insert Table 2 Approximately Here}

As documented by Morck, Yeung, and Yu (2000), the emerging market stocks tend to have high coefficient of determinations using a market model. This is confirmed in Table 2 using monthly returns. In particular, the $\mathrm{R}^{2} \mathrm{~s}$ ranged from $2 \%$ to $85 \%$ with an average level close to $50 \%$ over the whole sample period. The average beta in the recent sample period was 0.91 , which was lower than that in the whole sample period. This suggests that betas of large stocks have decreased recently, which is consistent with decreases in the $\mathrm{R}^{2}$ shown in the same table. When the stock market is very speculative, the turnover ratio should be relatively high. Average turnover during the sample period from 1993 to 2002 is indeed more than $600 \%$ ! It was still as high as 537\% during a more recent sample period of 1996-2002. With a round trip transactions costs over $1 \%$, it is likely that investors are more interested in short term trading gains than pursuing long term firm values during our sample period.

\subsection{The state's ownership structure and proxies}

A unique characteristic of the listed Chinese companies is that about $52 \%$ of the " $\mathrm{A}$ " shares are prohibited from trading (see Table 1). These shares include the state owned shares and the legal person shares ${ }^{6}$. The state shares are held by the central government, local governments, or solely state-owned enterprises. The legal person shares are owned by domestic institutions including other listed companies, state-owned enterprises that have at least one non-state owner, and nonbank financial institutions. Although both the state ownership and the legal person

\footnotetext{
${ }^{6}$ They are not tradable publicly at the stock exchanges. However, these shares can be transferred to domestic institutions upon the approval of CSRC. There are also a very small proportion of employee shares that are not tradable.
} 
ownership varied to some degree over time, the sum of the two was very stable as shown in Table 1. The rest of the shares - the floating shares can be traded at the exchanges?

The non-tradable share issue is the paramount issue facing the Chinese stock markets. It has generated problems for corporate governance and inefficiencies (see Chinese Corporate Governance Report 2003). The percentage of tradable shares could affect corporate governance, either directly or indirectly through the market for corporate control. From a signaling perspective, stocks with higher floating ratio, or the percentage of tradable shares, may enjoy higher returns since a high floating ratio could be associated with better governance. As suggested by Gompers, et al. (2003), an effective corporate governance signals a better performance in the long run. From a risk and return perspective, however, higher floating ratio means less risk as to government policies toward non-tradable shares. Therefore, firms with higher floating ratios should have lower expected returns other things being equal. Which effect is more significant is an empirical issue that will be tested in this paper. Given the importance of non-tradable shares in the Chinese market, we will first test its ability to explain the crosssectional differences in stock returns.

From cross-sectional perspective, the shareholding structure is also related to the market capitalization of individual stocks. In particular, the floating ratio is positively correlated with the $\log$ size variable with a correlation coefficient ranged from $30 \%$ to $40 \%$ as shown in Table 1 . The positive relationship indicates that, all else being equal, the higher the percentage of tradable shares is, the larger the market capitalization will be. Therefore, it is necessary to control for the size effect when estimating the impact of floating ratios on stock returns.

\footnotetext{
${ }^{7}$ There are two stock exchanges in China, the Shanghai and Shenzhen stock exchanges, and investors can freely trade stocks on both exchanges. There are no cross listings between the two exchanges.
} 


\section{Cross-sectional evidence on the Fama and French Three-factors}

In the CAPM world, differences in the expected returns of individual stocks are solely determined by the magnitude of the systematic risk measure beta. The surprising results provided by Fama and French (1992) told a different story. The log size variable and the bookto-market variable are very useful in separating individual stocks' expected return rather than the beta measure. If these two variables can be related to known risk factors definitely, the empirical findings of Fama and French are consistent with the ICAPM theory of Merton (1963). Although many papers have questioned the theoretical underpinning of the two additional factors (see for example, Berk, 1995; Jagannathan and Wang, 1996; Kothari, Shanken, and Sloan 1995; and Loughran, 1996), they remain to be the most useful factors from an empirical perspective for developed capital market equities. In this paper, we will further investigate the validity of these factors in a speculative market.

In the cross sectional regressions, we use monthly return data from July 1996 to June 2002. Following Fama and French (1992) and due to the total number of stock available, we first sort individual stocks into five groups according to their market size in June of each year. Within each size quintile, stocks are then sorted into ten portfolios according to their pre-betas. These pre-betas are estimated based on the previous 24 monthly returns. ${ }^{8}$ For any given year, the chosen stocks have to have at least two years of continuous record of monthly returns. For example the stocks we pick for the period from July 1996 to June 1997 were available in July 1994. The pre-betas for this period are constructed using the 24 monthly returns from July 1994 to June 1996. For the time series study of portfolio returns, we use monthly stock returns data from July 1995 to June 2002 with the first two year data used in sorting.

\subsection{Summary statistics for portfolio returns}

For a general view of the data set, we first report the average portfolio returns sorted on size and beta in Panel A of Table 3. The average portfolio returns varied sufficiently large from $0 \%$ to $3.2 \%$. There is a clear negative relationship between size and average return. However, there doesn't seem to be a pattern across beta sorted portfolios. Different from the U.S. data, the $\log$ portfolio size does not vary much as seen in Panel B of Table 3, which ranged from 12.6 to 14.6. In contrast, as demonstrated in Panel $\mathrm{C}$ of Table 3, the floating ratio fluctuated widely

\footnotetext{
${ }^{8} \mathrm{We}$ choose this period for study because the number of stocks in the initial years is not sufficiently large as shown in Table 1.
} 
from 0.19 to 0.51 across different portfolios. Again, as shown in Table 1, portfolios with higher average size tend to have fewer percentages of tradable shares.

\section{Insert Table 3 Approximately Here}

It is also interesting to ask where the size effect shown in Panel B comes from. Although the number of shares or the share price alone should not matter since their nominal to each other, one component may be more important than the other if the other component has no pattern across portfolios. The price component not only is stable over time but also offers no pattern as shown in Panel F. ${ }^{9}$ In contrast, most size effect seems to be captured by the variable of log shares shown in Panel D of Table 3. This is a unique phenomenon in the Chinese equity markets. Finally, we can examine the stability issue in the beta measure. The post-ranking portfolio beta estimated using portfolio returns displays a striking "no pattern" phenomenon. Stocks with relatively large pre-betas do not necessarily have high future betas. This is in sharp contrast with what has been observed in the US market and other mature markets. Several reasons may be plausible in affecting the post betas. When there are changes in the fundamental risk structure of individual companies due to shifts in their business models or in the economic environment including government policies which alters the sensitivities of different business, past betas may not persist. However, such massive structure changes have not occurred in China over our sample period, which makes this explanation unlikely. Alternatively, if the markets are highly speculative and economic fundamentals of individual stocks are of less importance, short term betas, such as the pre beta used in sorting can be largely governed by swings in market mood, which will be highly unstable.

Another variable shown to be useful in the Fama and French study is the book-to-market variable. After grouping individual stocks into five size groups, we have resorted each size group into ten portfolios according to individual stocks' June book-to-market value. The average portfolio returns are reported in Panel A of Table 4. Overall, portfolio average returns tend to increase with their book-to-market value. However, portfolio returns sorted according to their book-to-market values have less clear pattern compared to those sorted according to size.

\footnotetext{
${ }^{9}$ The difference between Panel B and Panel D of Table 3 is the log share price.
} 
Therefore, the book-to-market variable may be less powerful in explaining the cross-sectional difference in the Chinese stock returns.

\section{Insert Table 4 Approximately Here}

One unique feature about the Chinese stocks is the state ownership. As discussed before, such a unique structure may have affected the pricing of individual stocks. In other words, the floating ratio could be related to the expected returns of individual stocks. Different from Panel A of Table 4, we have also used the floating ratio in the second sort in Panel B of the same table. Not only there are large variations in portfolio returns ranging from $0 \%$ to $3.35 \%$, the variations across floating sorted portfolios are also substantial. More important, portfolio returns are positively related to the floating ratios. These general patterns will be confirmed in the crosssectional regression of the next section.

\subsection{The cross-sectional evidence}

The general pattern found in the previous section has to be tested rigorously. Fama-Mcbeth cross-sectional regression approach offers a powerful test in detecting pricing factors. Following Fama and French (1992), we report the cross-sectional regression results in Table 5 for different models. As shown in the U.S. data, the beta variable is also insignificant both used alone in equation I and used with other variables in equations VI, VIII, and IX. Similar to the U.S. experience, the size variable is highly significant with a negative sign as shown in equation II. It continues to be significant with control for the beta variable in equation VI. Therefore, the problem with the beta variable and the amazing size effect seem to be universal. They do not depend on the speculative nature of the markets. If log size is decomposed into log price and log

number of shares, the log share variable is significantly negative with approximately the same coefficient and significance as the log size variable (not shown in the table). Meanwhile, the log price is insignificant as expected from the discussion of Table 3.

Insert Table 5 Approximately Here 
The book-to-market variable, however, is statistically insignificant despite the correct sign in all the scenarios. Its magnitude is about the same as the log size variable. This is in contrast to Fama French's (1992) findings that book-to-market variable is the most powerful predictor of cross-sectional returns. Berk (1996) argues that book-to-market equity is a better predictor based on the fact that book value is a proxy for future cash flows. In an emerging market, such as the Chinese markets, investors understand that the book values are very inaccurate. It is, therefore, difficult to evaluate future cash flows based solely on a firm's book value. The lower magnitude and insignificance of book-to-market effect might not be of a big surprise. From this perspective, the book-to-market variable may indeed proximate the growth opportunities in the mature capital markets.

The floating ratio is positively related to return. However, it is insignificant by itself as shown in equation IV. This seems to contradicting to the results shown in Table 4. As shown in Table 1, the floating ratio is correlated with the log size variable. If the floating ratio is truly approximating for future cash flows in the Chinese markets, it will be less significant when it is contaminated by the negative size effect. This is exactly the case. When the size effect is taken away from the floating ratio, the residual floating ratio becomes statistically significant with a positive sign shown in equation V. When all the variables are used in equation VIII (or equation IX), both the magnitude and the significance of the floating ratio have improved. This also suggests that using the orthogonal part of floating ratio to the size variable in the cross-sectional regression is justified. Therefore, one should be cautious in applying the book-to-market variable in emerging capital markets. 


\section{The time series behavior of the three-factors}

The cross-sectional evidence is important in explaining the return difference for individual stocks. While the size effect remains important for the Chinese stock returns, the book to market effect has no power in cross-sectional tests. This result is robust and makes perfect sense in the Chinese investment environment where fundamentals were reported with less accuracy and thus were paid less attention by investors. In searching for unique pricing factors that determines Chinese stock returns, we have found that the floating ratio is more relevant than the book-tomarket variable. We argue that the floating ratio impacts corporate governance, which in turn affects future cash flows.

If the floating ratio truly reflects a pricing factor, one should be able to construct a return proxy from the characteristics sorted portfolio as in Fama and French (1993). Individual security returns should vary with this proxy over time according to the APT model. Therefore, we investigate the time series behavior of such a constructed proxy for Chinese equity in this section.

\subsection{Constructing proxy for the floating ratio}

Following Fama and French (1993), we have constructed proxies for size and floating ratio in the following way. In June of each year $t$ from 1995 to 2001, all stocks in our sample are ranked on size (market capitalization or price times number of tradable shares). Stocks are divided into two groups (small and big) with the same number of stocks. Independent to the size sorting, stocks are also ranked on the orthogonal floating ratios that are calculated from regressing float ratios on log market capitalization of all stocks on June of each year. According to their floating ratio sorting, stocks are divided into three groups (high, medium, low) with high and low groups containing about $30 \%$ of stocks each.

We then form six portfolios using equal weights from the intersection of the two size and tree float residual groups, which are used to construct proxies_-SMB and FR_HML for size and floating ratio, respectively. In particular SMB is the difference between the simple average of returns on the three small stock portfolios (Small/Low, Small/Medium, and Small/High) and the simple average of returns on the three big stock portfolios (Big/Low, Big/Medium, and Big/High). The FR_HML is the difference between the simple average of returns on the two high ratio portfolios (Small/High, and Big/High) and the two low ratio portfolios (Small/Low and Big/Low). 
Together with the market returns, these proxies are tested on the 25 size and floating ratio sorted portfolios. Different from the U.S. data, the differences in the market capitalization of traded Chinese companies are not too big. Therefore, we first sort all stocks into five groups with equal number according to size ${ }^{10}$. Each group of stocks is then sorted into five equal weighted portfolios with the equal number of stocks according to their floating ratio residuals.

\subsection{The properties of the constructed portfolios}

In order to study the dynamic performance of our proxy for the floating ratio, we need to be sure that the constructed portfolios are representative. The summary statistics for these 25 size and FR sorted portfolios are thus reported in Table 6.

\section{Insert Table 6 Approximately Here}

These portfolios have reasonable variations in terms of size from 251 million RMB (or 30 million dollar) to 2302 million RMB (or 277 million dollar). Although these Chinese companies may be classified as small-cap by the U.S. standard, these size numbers only represent one third of the total size due to none traded shares. When log size is used, the differences in size become much smaller. In contrast, the floating ratio changes from $6 \%$ to $68 \%$. Clearly, portfolio size and floating ratios are correlated to some degree as shown in Table 6 especially for portfolios with large floating ratio.

Average monthly portfolio returns vary from $1.9 \%$ to $5.3 \%$ with some patterns. One can consider portfolios in each row (column) as portfolios controlled for the size (ratio) effect. Average portfolio returns within each size group are clearly increasing with their ratios except the largest size group. At the same time, portfolio size has no pattern within each size group, which means any possible explanatory power in the floating ratio variable could not be attributed to correlation between size and the floating ratio. However, the relationship between size and average portfolio return after controlling for the ratio effect seems to be weaker. The negative relationship only holds for portfolios within the three smallest ratio groups. Moreover, the ratio

\footnotetext{
${ }^{10}$ Fama and French 1993 sort stocks by size and book to market independently. They construct portfolios that results from the intersection of the two-sorting approach. Due to limited number of stocks in the Chinese market, we first sort size then sort the float ratio residual in order to make sure that each portfolio has a relatively large number of stocks. The number of stocks in each portfolio is about 25 .
} 
variable also decreases with the average portfolio return within each ratio group. This suggests that the size effect could be due to the ratio effect. Since this analysis is in the spirit of "Granger causality," we conclude that the ratio effect "cause" the size effect in the Chinese equity market.

We have also reported summary statistics from fitting a market to the 25 portfolios in Table 6 as a base case to be compared to other models late on. In general, a single market factor captures between $60 \%$ and $94 \%$ of variations in the 25 portfolio returns. This is very similar to those observed the U.S. data despite the fact that $\mathrm{R}^{2} \mathrm{~s}$ are much higher for individual Chinese stocks due to diversification effect. One can consider alpha as the market risk adjusted return. Clearly portfolio alphas exhibit very similar pattern as the average portfolio returns discussed above with even weaker association with the size variable. At the same time, it is surprise to see that individual portfolio alphas are mostly insignificant at a 5\% level except for four portfolios in either the smallest or largest groups. In contrast, more than a third of the portfolios have had significant alphas in the U.S. data (see Fama and French, 1993). As shown in the cross-sectional results, betas do not seem to emerge any patterns with portfolio returns. Moreover, most portfolio betas are very close to one except for two portfolios.

\subsection{The time series performance of the constructed factor proxies}

We first study the performance of the size and FR ratio proxies alone in Table 7. In particular, each portfolio's excess returns are regressed against the mimicking portfolio returns for size (SMB) and float ratio (FR_HML). Most portfolios are loaded positively and significantly on the FR_HML variable except for four portfolios. In contrast, there are only eleven portfolios that are significantly loaded on the SMB variable. Most of these portfolios are from the two smallest size groups. The two factors are very useful in explaining the time variations in asset returns. The adjusted $\mathrm{R}^{2} \mathrm{~s}$ vary from $0 \%$ to $37 \%$ with an average of $18 \%$. It is also interesting to not that the two proxies have explained more variations in the small size but with large FR ratio portfolio returns. This is somewhat different from the U.S. data when both the size and the book-to-market proxies are used. In the U.S., $\mathrm{R}^{2} \mathrm{~s}$ are about the same across portfolios sorted along book-to-market dimension, but gradually decreases with the portfolio size. This suggests that the size effect is more concentrated in small stocks than large stocks, while the ratio effect is more significant on stocks with large ratios. 


\section{Insert Table 7 Approximately Here}

It is also important to examine the pattern in alpha again. In general, alphas from the two factor model are much larger than those from a market model shown in Table 6. In fact, alphas vary from $1.1 \%$ to $3.8 \%$ with nine of them being statistically significant. This means that the two factors cannot be used alone despite the fact that they capture reasonable time variations in asset returns.

We now investigate the full model with the market factor, SMB, and FR_HML in Table 8. Although the average beta for the market factor (0.98) remains to be close to one, the variations across individual portfolios' betas are much smaller than those from the market model shown in Table 6. In other words, the market factor explains a very similar portion of the variations in individual portfolio returns. Since there are reasonable variations across average portfolio returns and portfolio volatilities, market factor alone cannot explain them all. With the two additional factors added in, the average $\mathrm{R}^{2}$ has increased from $81 \%$ to $90 \%$. There are only eight

portfolios with $\mathrm{R}^{2}$ s below $90 \%$. The two factors have also helped to make the explanatory power of the three factor model more even across portfolios with a relatively small variation from $71 \%$ to $95 \%$. When we examine the performance of individual factors, the significance of the size factor has had a large boost, while the ratio effect seems to be weakened. The reducing power in the FR_HML proxy is primarily due to the moderate correlation between the market return and the factor. The enhancement in the size effect over time could be attributed to correlation between size and floating ratio. Since the improvement does not occur in the two factor model discussed above, it means that only the market adjusted FR_HML helps to reduce the noise in the SMB variable.

Insert Table 8 Approximately Here

Table 8 also shows that alphas have also come back to the level that is comparable to that of a market model. Moreover, only four portfolios have significant alpha estimates. What is more important is that there does not seem to have any patterns in these alpha estimates. Since betas are close to one and the average portfolio return is similar to the average alpha from the two factor model, a market factor is needed to bring the alpha to zero. This means that, despite the 
inability of beta in differentiating return difference across securities, a market factor is useful to explain why an average stock earns a higher return and why stock returns vary so much than that of a risk-free asset. In addition, variables such as SMB and FR_HML are needed to explain additional differences in return variations across stocks. Finally, we have also tried an additional one year momentum factor. This factor doesn't seem to improve R square. Loadings on most portfolios are insignificant. Momentum factors other than one year bear similar results. 


\section{Concluding Comments}

When the majority of investors are playing for short-term gains, not only security prices may be distorted but also the benefit of long term investment is limited. However, from the average trading volume and the participation rate in the Chinese stock markets, it is undisputable that they are a focal point in the Chinese economy. Therefore, it is important to study what factors determine the Chinese equity returns. Since we use the research results found in the mature capital markets such as the U.S. markets, this research also offers a benefit of testing the robustness of the important asset pricing factors using emerging market data.

From Fama and French (1992 and 1993) we have learned that a firm's market capitalization and book-to-market equity not only explains the cross-sectional differences in the average stock returns but also captures most differences in time variations in individual security returns. As argued that the boo-to-market variable approximates risks in a firm's fundamentals, one should not find this variable to be useful when either the book value of a firm is difficult to evaluate or investors do not pay much attention to fundamentals. Otherwise, the book-to-market variable must capture other unknown risk factors. The Chinese capital markets have provided us with such a unique environment, where corporate accounting standards are evasive and the markets are speculative. Indeed, the cross-sectional evidence shows that the book-to-market variable is useless in explaining the cross-sectional difference in equity returns. Therefore, one should be careful in using this variable in a different environment. The size effect, however, continues to be useful although somewhat weaker for the Chinese stocks.

In contrast, we argue that the unique non-tradable shares or the float ratio signals the quality of corporate governance in China which will affect firms' future cash flows. In this sense, it is a better proxy for a Chinese firm's growth potential and investment opportunity than the book-tomarket variable which is popular in the mature market. We have shown that this variable is very useful in understanding the cross-sectional return differences for Chinese stocks. In this case the popular Fama and French three-factor model should be revised to include a proxy for the floating ratio instead of the boo-to-market proxy. The time series evidence suggests that such a threefactor model can explain $90 \%$ of the variation in portfolio returns, which reflects a $10 \%$ improvement over a simple market model. 


\section{References}

Berk, J. (1995), “A Critique of Size-Related Anomalies,” Review of Financial Studies, Vol. 8, pp. 275-286.

Black, F. (1972), "Capital market Equilibrium with Restricted Borrowing," Journal of Business, Vol. 45, pp. 444-454.

Chen, N., R. Roll, and S. A. Ross (1986), "Economic Forces and the Stock Markets," Journal of Business, Vol. 59, pp. 383-403.

Cochrane, J. H. (2001), Asset Pricing, Princeton University Press: Princeton.

Campbell, J.Y., M. Lettau, B.G. Malkiel, and Y. Xu, 2001, "Have Individual Stocks Become More Volatile? An Empirical Exploration of Idiosyncratic Risk," Journal of Finance, 56, 1:43.

Chan L., Y. Hamao, and J. Lakonishok, 1991, "Fundamentals and Stock Returns in Japan," Journal of Finance, 46, 1739-1764.

Daniel, K., S. Titman, and K.C.J. Wei, 2001, "Explaining the Cross-Section of Stock Returns in Japan," Journal of Finance, 56, 743-756.

Durnev, A., R. Morck, B. Yeung, and P. Zarowin, 2002, "Does Greater Firm-Specific Return Variation Mean More or Less Informed Stock Trading?” Working Paper, New York University.

Fama, E. and J. MacBeth (1973), "Risk, Return, and Equilibrium: Empirical Tests," Journal of Political Economy, Vol. 81, pp. 607-636.

Fama, Eugene F. and French, Kenneth R. (1996), "Multifactor Explanations of Asset Pricing Anomalies," Journal of Finance, Vol. 51, pp. 55-84.

Fama, Eugene F., and Kenneth R. French (1993), "Common Risk Factors in the Returns on Stock and Bonds," Journal of Financial Economics, Vol.33, pp.3-56.

Fama, Eugene F., and Kenneth R. French (1992), "The Cross-Section of Expected Stock Returns," Journal of Finance, Vol.47, pp.427-465.

Gompers, Paul A., Joy L. Ishii, andAndrew Metrick (2003), "Corporate Governance Equity Prices," Quarterly Journal of Economics, Vol.118(1), pp. 107-155.

Jagannathan, Ravi, and Zhenyu Wang (1996), "The Conditional CAPM and the Cross-Section of Expected Returns," Journal of Finance, Vol. 51, pp. 3-53.

Jensen, M., 1986, “Agency Costs of Free Cash Flow, Corporate Finance and Takeovers," American Economic Review, 76, 323-329. 
Kothari, S.P., Jay Shanken, and Richard G. Sloan (1995), "Another Look at the Cross-Section of Expected Stock Returns,” Journal of Finance, Vol. 50, pp. 185-244.

Lintner, John (1965), "The Valuation of Risky Assets and the Selection of Risky Investment in Stock Portfolio and Capital Budgets," Review of Economics and Statistics, Vol. 47, pp. 13-37.

Loughran, Tim (1996), "Book-to-Market Across Firm Size, Exchange, and Seasonality: Is There an Effect?” Working Paper, University of Iowa.

Malkiel, B. G., and Y. Xu (2000), "Idiosyncratic Risk and Security Returns," Working Paper, School of Management, The University of Texas at Dallas.

Miller, M. H. and M. Scholes (1972), 'Rates and Return in Relation to Risk: A Re-examination of Some Recent Findings,' in Michael C. Jensen, ed.: Studies in the Theory of Capital Markets, Praeger: New York, pp. 47-78.

Morck, R., B. Yeung, and W. Yu, 1999, "Why Do Emerging Markets Have Synchronous Stock Price Movements?" Working Paper, University of Alberta.

Sharpe, William F. (1964), "Capital Asset Prices: A Theory of Market Equilibrium under Conditions of Risk," Journal of Finance, Vol. 19, pp. 425-442.

Xu, Y. (2003) "Diversification in the Chinese Stock Market", Working Paper, School of Management, The University of Texas at Dallas. 
Table 1. Summary Statistics for A-share Stocks Traded on Both Stock Exchanges

This table reports summary statistics for non-financial A-share stocks in our sample. All statistics are measured in the end of a certain year. $\mathbf{N}$ stands for the number of firms. FR stands for the floating ratio, the percentage of tradable shares. SS stands for state shares. LPS stands for Legal Person Shares. MCP stands for the market capitalization of a firm's tradable shares, and is measure in million RMB (The number in square brackets are mean market capitalizations in million US dollars. "s.d." stands for standard deviation of RMB denominated MCP). Correlation stands for the correlation between float ratio and log market capitalization. Mean share price is in RMB (The numbers in square brackets are mean share prices in US Dollars. "s.d." stands for standard deviation of RMB denominated share prices).

\begin{tabular}{c|c|c|c|c|c|c|c|c|c|c}
\hline & $\mathbf{1 9 9 3}$ & $\mathbf{1 9 9 4}$ & $\mathbf{1 9 9 5}$ & $\mathbf{1 9 9 6}$ & $\mathbf{1 9 9 7}$ & $\mathbf{1 9 9 8}$ & $\mathbf{1 9 9 9}$ & $\mathbf{2 0 0 0}$ & $\mathbf{2 0 0 1}$ & $\mathbf{2 0 0 2}$ \\
\hline $\mathbf{N}$ & 177 & 287 & 311 & 514 & 720 & 825 & 923 & 1033 & 1135 & 1195 \\
\hline Mean Price & 12.56 & 7.49 & 5.53 & 10.38 & 11.43 & 10.41 & 11.02 & 16.72 & 12.04 & 9.22 \\
[US\$] & {$[1.51]$} & {$[0.90]$} & {$[0.67]$} & {$[1.25]$} & {$[1.38]$} & {$[1.25]$} & {$[1.33]$} & {$[2.01]$} & {$[1.45]$} & {$[1.11]$} \\
(s.d.) & $(6.36)$ & $(4.40)$ & $(2.81)$ & $(4.90)$ & $(6.16)$ & $(4.83)$ & $(5.50)$ & $(7.34)$ & $(4.92)$ & $(3.96)$ \\
\hline Share Prices & 6.3 & 3.33 & 2.8 & 5.2 & 5.8 & 5.6 & 5.89 & 9.35 & 6.96 & 5.3 \\
at the 10, 50, & 10.95 & 6 & 4.78 & 9.53 & 9.59 & 9.36 & 9.58 & 15.16 & 11.13 & 8.23 \\
\& 90 percentiles & 20.5 & 13.35 & 8.95 & 16.52 & 19.3 & 16.65 & 17.87 & 25.6 & 18.1 & 14.13 \\
\hline Mean MCP & 379 & 277 & 255 & 486 & 668 & 668 & 853 & 1467 & 1173 & 973 \\
[ in US\$] & {$[46]$} & {$[33]$} & {$[31]$} & {$[59]$} & {$[81]$} & {$[80]$} & {$[103]$} & {$[176]$} & {$[141]$} & {$[117]$} \\
(s.d.) & $(425)$ & $(265)$ & $(227)$ & $(712)$ & $(1228)$ & $(785)$ & $(946)$ & $(1263)$ & $(998)$ & $(958)$ \\
\hline MCP at 10, & 101 & 114 & 95 & 141 & 188 & 240 & 310 & 613 & 498 & 383 \\
50, and 90 & 258 & 207 & 191 & 327 & 448 & 500 & 636 & 1168 & 911 & 713 \\
percentiles & 721 & 476 & 418 & 887 & 1268 & 1228 & 1521 & 2476 & 2005 & 1710 \\
\hline Mean FR & 0.260 & 0.295 & 0.313 & 0.300 & 0.303 & 0.306 & 0.323 & 0.349 & 0.359 & 0.363 \\
(s. d.) & $(0.169)$ & $(0.172)$ & $(0.178)$ & $(0.151)$ & $(0.135)$ & $(0.129)$ & $(0.131)$ & $(0.137)$ & $(0.136)$ & $(0.135)$ \\
\hline FR at 10, & 0.069 & 0.090 & 0.089 & 0.119 & 0.135 & 0.151 & 0.162 & 0.176 & 0.199 & 0.203 \\
50, and 90 & 0.25 & 0.270 & 0.301 & 0.271 & 0.284 & 0.288 & 0.309 & 0.333 & 0.351 & 0.358 \\
percentiles & 0.477 & 0.516 & 0.536 & 0.488 & 0.473 & 0.462 & 0.475 & 0.521 & 0.535 & 0.537 \\
\hline Mean Percent SS & 0.318 & 0.310 & 0.307 & 0.303 & 0.316 & 0.282 & 0.272 & 0.314 & 0.330 & 0.337 \\
(s.d.) & $(0.277)$ & $(0.271)$ & $(0.262)$ & $(0.259)$ & $(0.265)$ & $(0.266)$ & $(0.267)$ & $(0.265)$ & $(0.266)$ & $(0.265)$ \\
\hline Mean Percent LPS & 0.202 & 0.208 & 0.198 & 0.211 & 0.203 & 0.245 & 0.245 & 0.208 & 0.199 & 0.191 \\
(s.d.) & $(0.264)$ & $(0.270)$ & $(0.257)$ & $(0.257)$ & $(0.257)$ & $(0.270)$ & $(0.271)$ & $(0.255)$ & $(0.251)$ & $(0.247)$ \\
\hline correlation & 0.391 & 0.304 & 0.312 & 0.357 & 0.314 & 0.362 & 0.352 & 0.416 & 0.343 & 0.290 \\
(significance) & $(0.000)$ & $(0.000)$ & $(0.000)$ & $(0.000)$ & $(0.000)$ & $(0.000)$ & $(0.000)$ & $(0.000)$ & $(0.000)$ & $(0.000)$ \\
\hline
\end{tabular}




\section{Table 2. Characteristics of Sample Data during Two Sample Periods}

Market Return stands for average monthly return for the market index, constructed as the value weighted average monthly stock returns of all the tradable shares in the sample. Monthly Individual Stock Return is the time series averages of individual stock's monthly returns. Average Monthly individual stock return is the cross sectional average of monthly individual stock returns. Beta and $\mathrm{R}^{2}$ are respectively the estimated coefficient, and coefficient of determination from a market model using monthly returns over the specified sample period. The monthly market model is specified as $\mathrm{R}_{\mathrm{i}, t}-\mathrm{R}_{\mathrm{f}, \mathrm{t}}=\alpha+\beta_{\mathrm{i}} *\left(\mathrm{R}_{\mathrm{m}, \mathrm{t}}-\mathrm{Rf}_{\mathrm{t}}\right)+\mathrm{e}_{\mathrm{i}, \mathrm{t}}$, where $\mathrm{R}$ is the individual stock $i$ 's return, $\mathrm{R}_{\mathrm{m}}$ is the market return, and $R_{f}$ is the bank current account monthly interest rate. Stocks that were exist in January 2001 (a total of 1034 stocks) are all included in computing these betas and $\mathrm{R}^{2}$ s. Average Beta is the cross sectional average of individual stocks' betas for the specified period. Mean $\mathbf{R}^{2}$ is the cross sectional average of individual stocks' $\mathrm{R}^{2} \mathrm{~s}$ for the specified period. Average Turnover is defined as the average of the annual market turnover ratios during the specified period. The annual market turnover ratio is the ratio of the sum of annual trading volume of all the stocks to the end of year market capitalization of the tradable shares.

\begin{tabular}{c|c|c}
\hline & $\mathbf{1 9 9 3 - 2 0 0 2}$ & $\mathbf{1 9 9 6 - 2 0 0 2}$ \\
\hline Market Return & 0.021 & 0.021 \\
(s.d) & $(0.158)$ & 0.091 \\
\hline Market Return at 10, & -0.113 & -0.072 \\
$\mathbf{5 0 ~ \& ~ 9 0 ~ P e r c e n t i l e s ~}$ & 0.004 & 0.007 \\
& 0.146 & 0.123 \\
\hline Average Monthly Individual & 0.005 & 0.005 \\
Stock Return (s.d.) & $(0.021)$ & $(0.022)$ \\
\hline Monthly Individual Stock Return & -0.021 & -0.021 \\
at 10, 50 \& 90 Percentiles & 0.010 & 0.010 \\
& 0.025 & 0.027 \\
\hline Average Beta & 0.93 & 0.91 \\
(s.d.) & $(0.24)$ & $(0.25)$ \\
\hline Mean R & 0.49 & 0.43 \\
(s.d.) & $(0.17)$ & $(0.14)$ \\
\hline Average turnover & 6.12 & 5.37 \\
\hline
\end{tabular}


Table 3. Summary Statistics for Portfolios Formed on Size and Beta: July 1996 to July 2002 Portfolios are formed annually. The breakpoints for the size quintiles are determined in June of each year with approximately the same number of stocks. Each size quintile is equally subdivided into ten beta portfolios according to pre-ranking betas of individual stocks estimated using 24 monthly returns prior to June of each year. The following twelve month returns for the 50 portfolio are then calculated using equal weights. The average size, the number of shares, and the float ratio of a portfolio are the time-series averages of the monthly $\ln (\mathrm{ME})$, the monthly $\ln$ (NShrs), and monthly floating ratios for stocks in the portfolio. ME (value of all tradable shares) is denominated in thousand of RMB. Nshrs is the number of shares in thousand. The post-ranking beta is estimated uses the full (July 1996 to June 2002) sample returns of each portfolio. The implied $\ln ($ Price) is the difference between elements in panel B and the corresponding numbers in panel D.

\begin{tabular}{|c|c|c|c|c|c|c|c|c|c|c|c|}
\hline \multicolumn{12}{|c|}{ Panel A: Average Monthly Return } \\
\hline & All & $\begin{array}{c}\text { Small } \\
\text { beta }\end{array}$ & & & & & & & & & $\begin{array}{c}\text { Large } \\
\text { beta }\end{array}$ \\
\hline All & & $1.44 \%$ & $1.57 \%$ & $1.90 \%$ & $1.88 \%$ & $1.55 \%$ & $1.50 \%$ & $1.65 \%$ & $1.41 \%$ & 1. $44 \%$ & $0.98 \%$ \\
\hline \multirow[t]{4}{*}{ Small-ME } & $2.42 \%$ & $2.42 \%$ & $2.53 \%$ & $3.14 \%$ & $2.25 \%$ & $2.11 \%$ & $2.90 \%$ & $2.13 \%$ & $2.45 \%$ & 2. $74 \%$ & $1.58 \%$ \\
\hline & $2.06 \%$ & $1.61 \%$ & $1.74 \%$ & $2.13 \%$ & $2.74 \%$ & $2.11 \%$ & $2.37 \%$ & $2.48 \%$ & $1.82 \%$ & $1.97 \%$ & $1.58 \%$ \\
\hline & $1.50 \%$ & $1.45 \%$ & $1.57 \%$ & $1.70 \%$ & $1.60 \%$ & $1.69 \%$ & $1.57 \%$ & $1.96 \%$ & $1.35 \%$ & $1.64 \%$ & $0.47 \%$ \\
\hline & $0.96 \%$ & $0.72 \%$ & $1.38 \%$ & $1.00 \%$ & $1.62 \%$ & $1.05 \%$ & $0.77 \%$ & $0.84 \%$ & $0.62 \%$ & $0.59 \%$ & $1.01 \%$ \\
\hline Large-ME & $0.77 \%$ & $1.05 \%$ & $0.67 \%$ & $1.58 \%$ & $1.20 \%$ & $0.83 \%$ & $0.05 \%$ & $0.82 \%$ & $0.88 \%$ & $0.28 \%$ & $0.36 \%$ \\
\hline \multicolumn{12}{|c|}{ Panel B: $\ln (\mathrm{ME})$} \\
\hline All & & 13.74 & 13.75 & 13.77 & 13.77 & 13.73 & 13.78 & 13.75 & 13.76 & 13.78 & 13. 74 \\
\hline \multirow[t]{4}{*}{ Small-ME } & 12.95 & 12.84 & 12.90 & 12.97 & 12.94 & 12.83 & 12.95 & 13.00 & 13.05 & 13.09 & 12.96 \\
\hline & 13.41 & 13.38 & 13. 34 & 13.42 & 13.43 & 13.44 & 13.48 & 13.44 & 13.37 & 13.44 & 13.39 \\
\hline & 13.70 & 13.73 & 13.76 & 13.74 & 13.71 & 13.72 & 13.66 & 13.72 & 13.66 & 13.73 & 13.58 \\
\hline & 14.02 & 14.01 & 14. 08 & 14.03 & 14.06 & 14.03 & 14.05 & 14.00 & 13.97 & 13.97 & 14.00 \\
\hline Large-ME & 14.65 & 14.69 & 14.61 & 14.66 & 14.68 & 14.61 & 14.66 & 14.61 & 14.67 & 14.65 & 14.66 \\
\hline \multicolumn{12}{|c|}{ Panel C: Float Ratio } \\
\hline All & & 0.336 & 0.331 & 0.336 & 0.345 & 0.366 & 0.353 & 0.365 & 0.373 & 0.387 & 0.364 \\
\hline \multirow[t]{4}{*}{ Small-ME } & 0.250 & 0.247 & 0.214 & 0.220 & 0.267 & 0.248 & 0.223 & 0.232 & 0.295 & 0.296 & 0.255 \\
\hline & 0.346 & 0.318 & 0.322 & 0.342 & 0.351 & 0.345 & 0.357 & 0.364 & 0.326 & 0.390 & 0.346 \\
\hline & 0.363 & 0.352 & 0.361 & 0.376 & 0.362 & 0.385 & 0.357 & 0.368 & 0.344 & 0.387 & 0.338 \\
\hline & 0.383 & 0.376 & 0.374 & 0.324 & 0.372 & 0.404 & 0.399 & 0.376 & 0.401 & 0.397 & 0.412 \\
\hline Large $-\mathrm{ME}$ & 0.432 & 0.381 & 0.379 & 0.414 & 0.369 & 0.443 & 0.417 & 0.487 & 0.493 & 0.467 & 0.460 \\
\hline \multicolumn{12}{|c|}{ Pane1 D: $\ln ($ Nshrs $)$} \\
\hline & & $\begin{array}{l}\text { Low } \\
\text { Beta }\end{array}$ & & & & & & & & & $\begin{array}{l}\text { High } \\
\text { Beta }\end{array}$ \\
\hline \multirow{5}{*}{ Small-ME } & & 11.17 & 11.20 & 11.26 & 11.31 & 11.25 & 11.29 & 11.21 & 11.23 & 11.21 & 11. 13 \\
\hline & 10.31 & 10.12 & 10.29 & 10.28 & 10.31 & 10.26 & 10.31 & 10.32 & 10.42 & 10.42 & 10. 34 \\
\hline & 10.88 & 10.87 & 10.76 & 10.94 & 11.00 & 10.91 & 10.96 & 10.90 & 10.81 & 10.87 & 10.74 \\
\hline & 11.25 & 11.17 & 11.26 & 11.25 & 11.33 & 11.30 & 11.36 & 11.18 & 11.26 & 11.27 & 11.11 \\
\hline & 11. 56 & 11.50 & 11.56 & 11.65 & 11.58 & 11.63 & 11.61 & 11.65 & 11.49 & 11.51 & 11. 43 \\
\hline Large-ME & 12.09 & 12.15 & 12.08 & 12.12 & 12.27 & 12.10 & 12.10 & 12.01 & 12.11 & 12.01 & 11.92 \\
\hline
\end{tabular}


Panel E: Post-Ranking betas

\begin{tabular}{|c|c|c|c|c|c|c|c|c|c|c|c|}
\hline & & 1.01 & 1. 13 & 1.13 & 1.01 & 0.98 & 1.01 & 1.02 & 1. 10 & 0.97 & 0.96 \\
\hline \multirow[t]{4}{*}{ Small-ME } & 1.00 & 0.98 & 1. 18 & 1.27 & 0.95 & 0.89 & 1.12 & 0.80 & 0.87 & 0.72 & 0.69 \\
\hline & 1.08 & 0.94 & 1. 12 & 0.89 & 1.28 & 1.11 & 1.08 & 1.20 & 0.97 & 0.96 & 0.83 \\
\hline & 1.05 & 1.01 & 1.03 & 1.13 & 1.00 & 0.93 & 1.39 & 1.08 & 0.93 & 0.99 & 0.73 \\
\hline & 1.05 & 1.00 & 1. 18 & 1.12 & 1.04 & 1.02 & 0.90 & 0.86 & 1. 14 & 0.95 & 1. 12 \\
\hline Large-ME & 1.02 & 1.00 & 1.11 & 1.13 & 0.92 & 0.96 & 0.88 & 1.01 & 1.14 & 0.97 & 0.98 \\
\hline \multicolumn{12}{|c|}{ Panel F: Implied ln(Price) } \\
\hline \multirow{5}{*}{ Small-ME } & & 2. 57 & 2.55 & 2. 51 & 2. 47 & 2. 48 & 2. 49 & 2.54 & 2. 53 & 2. 56 & 2. 61 \\
\hline & 2.64 & 2. 72 & 2.60 & 2.69 & 2.63 & 2. 57 & 2.65 & 2. 68 & 2. 63 & 2. 67 & 2. 61 \\
\hline & 2.54 & 2. 51 & 2. 59 & 2. 48 & 2. 43 & 2.52 & 2. 52 & 2. 53 & 2. 56 & 2. 58 & 2.65 \\
\hline & 2.45 & 2. 56 & 2. 51 & 2. 48 & 2. 38 & 2. 42 & 2. 30 & 2. 54 & 2. 41 & 2. 46 & 2. 47 \\
\hline & 2. 46 & 2. 51 & 2. 52 & 2. 37 & 2. 48 & 2. 40 & 2. 44 & 2. 35 & 2. 48 & 2. 46 & 2. 58 \\
\hline Large-ME & 2.56 & 2.54 & 2. 53 & 2. 54 & 2.41 & 2. 51 & 2. 55 & 2. 61 & 2. 56 & 2.65 & 2. 74 \\
\hline
\end{tabular}


Table 4. Average Monthly Returns on Alternative Portfolio Sorting Method: July 1996 to June 2002

This table reports portfolio returns formed according to size and boo-to-market sorting as well as size and floating ratio sorting. In June of each year, all the stocks are equally allocated to five size portfolios. The stocks in each quintile are then sorted into ten BE/ME portfolios using the book-to-market ratios in Panel A and ten floating Ratio portfolios using the floating ratios in Panel B. BE/ME is the book value of common equity over market equity. Each portfolio returns are then calculated using equal weights. The All column shows average returns for equalweighted size quintile portfolios. The All row shows average returns for equal-weighted portfolios in each BE/ME group in Panel A and equal-weighted portfolios in each Ratio group in Panel B.

\begin{tabular}{|c|c|c|c|c|c|c|c|c|c|c|c|}
\hline & ALL & $\begin{array}{c}\text { Low } \\
\text { BE/ME }\end{array}$ & & & & & & & & & $\begin{array}{c}\text { High } \\
\text { BE/ME }\end{array}$ \\
\hline ALL & & $1.12 \%$ & $1.24 \%$ & $1.37 \%$ & $1.25 \%$ & $1.58 \%$ & $1.93 \%$ & $2.02 \%$ & $2.18 \%$ & $1.92 \%$ & 1. $70 \%$ \\
\hline \multirow[t]{4}{*}{ Small-ME } & $2.62 \%$ & $2.50 \%$ & $2.49 \%$ & $2.66 \%$ & $1.93 \%$ & $2.53 \%$ & $2.98 \%$ & $3.08 \%$ & $2.84 \%$ & $2.92 \%$ & $2.25 \%$ \\
\hline & 2. $12 \%$ & $1.47 \%$ & $1.24 \%$ & $1.89 \%$ & $1.56 \%$ & $2.30 \%$ & 2. $45 \%$ & $2.64 \%$ & $2.91 \%$ & $2.59 \%$ & $2.09 \%$ \\
\hline & 1. $55 \%$ & $0.77 \%$ & 1. $34 \%$ & $1.78 \%$ & $1.45 \%$ & $1.53 \%$ & $1.21 \%$ & $1.54 \%$ & $2.59 \%$ & $1.59 \%$ & $1.63 \%$ \\
\hline & $1.08 \%$ & $0.29 \%$ & $0.40 \%$ & $0.58 \%$ & $0.93 \%$ & $0.99 \%$ & 1. $46 \%$ & 1. $71 \%$ & $1.61 \%$ & $1.30 \%$ & 1. $49 \%$ \\
\hline Large-ME & $0.84 \%$ & $0.72 \%$ & $0.70 \%$ & $0.07 \%$ & $0.44 \%$ & $0.59 \%$ & $1.53 \%$ & $1.18 \%$ & $0.96 \%$ & $1.21 \%$ & $1.04 \%$ \\
\hline \multicolumn{12}{|c|}{ Pane1 B: Size and floating ratio } \\
\hline & A11 & $\begin{array}{c}\text { Low } \\
\text { Ratio }\end{array}$ & & & & & & & & & $\begin{array}{l}\text { High } \\
\text { Ratio }\end{array}$ \\
\hline All & & $1.13 \%$ & $1.33 \%$ & $1.35 \%$ & $1.56 \%$ & $1.39 \%$ & $1.61 \%$ & 1. $75 \%$ & $2.07 \%$ & $2.30 \%$ & 1. $83 \%$ \\
\hline \multirow[t]{4}{*}{ Small-ME } & $2.62 \%$ & $1.78 \%$ & $1.61 \%$ & $2.55 \%$ & $2.65 \%$ & $2.86 \%$ & $2.50 \%$ & $2.33 \%$ & 3. $35 \%$ & $3.60 \%$ & $2.91 \%$ \\
\hline & 2. $12 \%$ & $1.30 \%$ & $2.26 \%$ & $1.92 \%$ & $1.45 \%$ & $2.14 \%$ & $2.33 \%$ & $2.67 \%$ & $2.19 \%$ & $2.92 \%$ & $1.94 \%$ \\
\hline & 1. $55 \%$ & $1.45 \%$ & $1.13 \%$ & $1.04 \%$ & $1.64 \%$ & $1.16 \%$ & 1. $34 \%$ & $1.68 \%$ & $2.28 \%$ & $2.08 \%$ & $1.67 \%$ \\
\hline & $1.08 \%$ & $0.67 \%$ & $1.23 \%$ & $0.64 \%$ & $0.95 \%$ & $0.81 \%$ & $1.00 \%$ & $1.27 \%$ & $1.49 \%$ & $1.40 \%$ & $1.36 \%$ \\
\hline Large-ME & $0.84 \%$ & $0.49 \%$ & $0.46 \%$ & $0.66 \%$ & $1.14 \%$ & $0.01 \%$ & $0.93 \%$ & $0.82 \%$ & $1.03 \%$ & $1.58 \%$ & $1.33 \%$ \\
\hline
\end{tabular}




\section{Table 5. Cross-sectional Regression for Different Models: July 1996 to June 2002.}

This table shows test results for each model based on the cross-sectional regressions. Individual stocks are assigned the post-ranking portfolio betas (Beta) estimated from the size-beta forted portfolio returns. $\ln (\mathbf{M E})$, is the $\log$ market value of tradable shares, which is measured in June of each year. BE/ME is the book value of common equity over market value of all shares (number of shares outstanding times price) for December of each year. FRratio (floating ratio), is the percentage of tradable shares that is measured in December of each year. Resid. FRratio (the residual float ratio), is the residual from a regression of FRratio on $\ln (\mathrm{ME})$. Price (share price) is measured in June of each year. NShr (number of shares) is measured in June of year each. All the variables above are matched with individual stock monthly returns from July of year $\mathrm{t}$ to June to year $\mathrm{t}+1$. $t$ statistics are reported in brackets.

\begin{tabular}{|c|c|c|c|c|c|c|c|}
\hline Equation & Beta & Ln(ME) & Ln(BE/ME) & FRratio & Resid. FRratio & Ln(Price) & Ln(NShr) \\
\hline I & $\begin{array}{l}-0.0126 \\
(-2.423) \\
\end{array}$ & & & & & & \\
\hline II & & $\begin{array}{l}-0.00796 \\
(-2.489)\end{array}$ & & & & & \\
\hline III & & & $\begin{array}{l}0.01148 \\
(1.613)\end{array}$ & & & & \\
\hline IV & & & & $\begin{array}{l}0.01937 \\
(1.554)\end{array}$ & & & \\
\hline $\mathrm{V}$ & & & & & $\begin{array}{l}0.03848 \\
(2.846)\end{array}$ & & \\
\hline VI & $\begin{array}{l}-0.0067 \\
(-1.275)\end{array}$ & $\begin{array}{l}-0.008148 \\
(-2.555)\end{array}$ & & & & & \\
\hline VII & & $\begin{array}{l}-0.009542 \\
(-2.836)\end{array}$ & $\begin{array}{l}0.01166 \\
(1.579)\end{array}$ & & & & \\
\hline VIII & $\begin{array}{l}-0.001959 \\
(-0.6061)\end{array}$ & $\begin{array}{l}-0.011874 \\
(-3.335)\end{array}$ & $\begin{array}{l}0.01036 \\
(1.5012)\end{array}$ & $\begin{array}{l}\mathbf{0 . 0 3 4 6 7} \\
(3.2325)\end{array}$ & & & \\
\hline IX & $\begin{array}{l}-0.001959 \\
(-0.6061)\end{array}$ & $\begin{array}{l}-0.009443 \\
(-2.875)\end{array}$ & $\begin{array}{l}0.01036 \\
(1.5012)\end{array}$ & & $\begin{array}{l}0.03467 \\
(3.2325)\end{array}$ & & \\
\hline $\mathrm{X}$ & $\begin{array}{l}-0.00334 \\
(-1.0641)\end{array}$ & & $\begin{array}{l}0.01037 \\
(1.8649) \\
\end{array}$ & & $\begin{array}{l}0.03240 \\
(3.2602)\end{array}$ & $\begin{array}{l}-0.00043 \\
(-0.6469) \\
\end{array}$ & $\begin{array}{l}-0.00958 \\
(-3.4949) \\
\end{array}$ \\
\hline
\end{tabular}


Table 6. Descriptive Statistics for 25 Portfolios Formed on Size and Floating Ratio: July 1995 to June 2002

This table reports the summary statistics for the 25 size and residual floating ratio sorted portfolios. In June each year from 1995 to 2002, quintile breakpoints for size (stock price times number of tradable shares) are used to allocate all stocks in the sample to five size groups with equal number of stocks. Stocks in each size quintile are then sorted by their orthogonal floating ratios (residuals) into five portfolios with equal number of stocks. The residuals are calculated from a regression of floating ratios on log market capitalizations for all the stocks and all the months. The descriptive statistics in Panel A, B, C, and E are computed using the whole sample data. In panel D, the average portfolio monthly return for a portfolio is the time series average of monthly returns from July 1995 to June 2002. We also report results (coefficients and $t$ values) from regressing each portfolio excess returns on the excess market return, or $\left(\mathrm{R}_{\mathrm{t}}-\mathrm{R}_{\mathrm{f}, \mathrm{t}}\right)=\alpha+\beta\left(\mathrm{R}_{\mathrm{m}, \mathrm{t}}-\mathrm{R}_{\mathrm{f}, \mathrm{t}}\right)+\mathrm{e}_{\mathrm{t}}$, from July 1995 to June 2002. $\mathrm{R}_{\mathrm{t}}, \mathrm{R}_{\mathrm{m}, \mathrm{t}}$ and $\mathrm{R}_{\mathrm{f}, \mathrm{t}}$ are the portfolio return, the value weighted market index return, and the risk-free rate at time t, respectively. $R^{2}$ is the adjusted coefficient of determination from this regression.

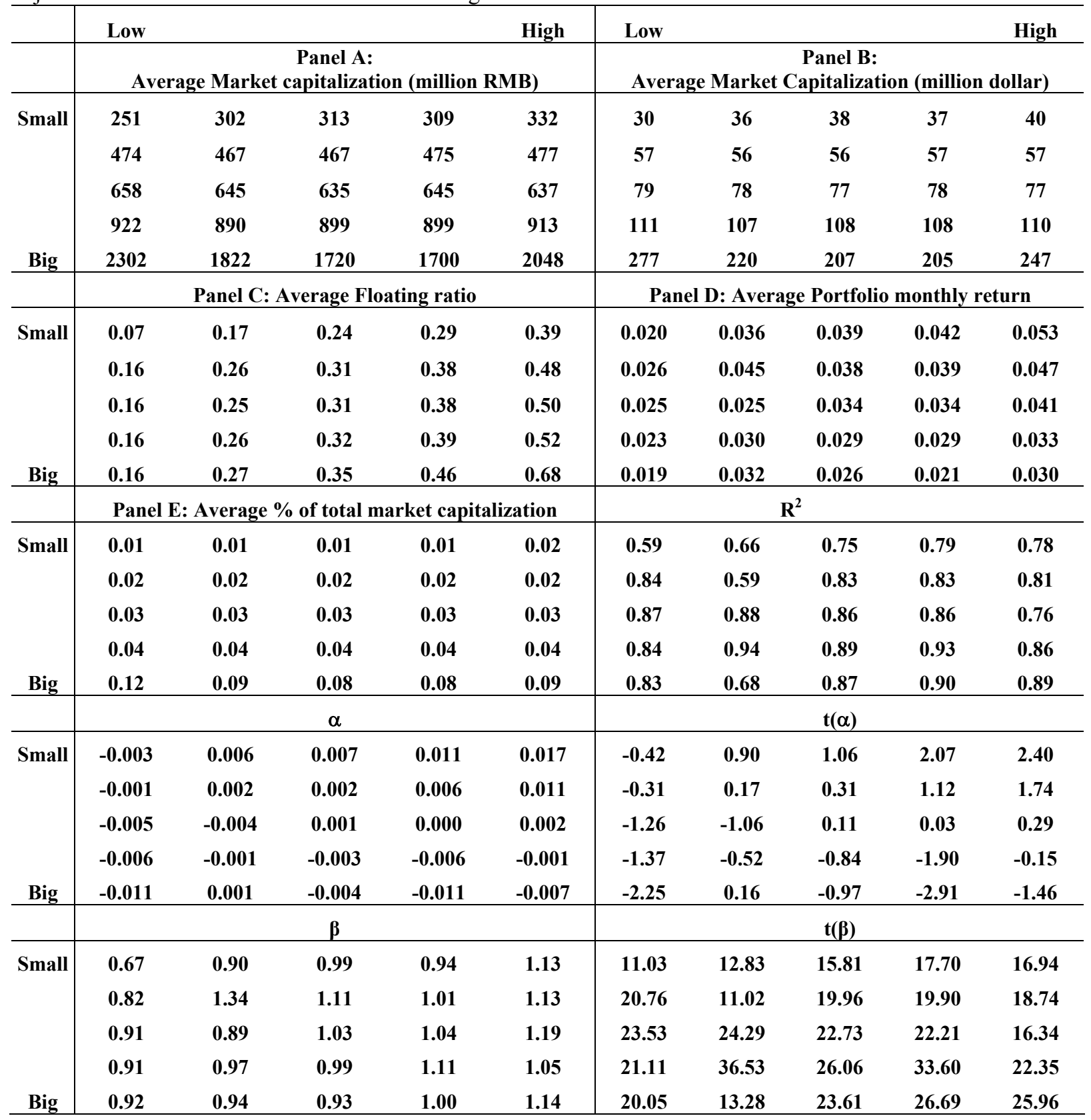


Table 7. Regression of Portfolio Returns from July 1995 to June 2002 on the Size Proxy and the Floating Ratio Proxy Only

This table shows results (coefficients and $t$ values) from regressing each portfolio's excess returns on proxies to the SMB and the FR_HML factors, or $\mathrm{R}_{\mathrm{t}}-\mathrm{R}_{\mathrm{f}, \mathrm{t}}=\alpha+s \mathrm{SMB}_{\mathrm{t}}+h \mathrm{FR} \mathrm{HML}_{\mathrm{t}}+\mathrm{e}_{\mathrm{t}}$, for the sample period from July 1995 to June 2002. The 25 portfolios are constructed as in table 6 . SMB is the return on the mimicking portfolio for the size effect. FR_HML is the mimicking portfolio return for the floating ratio effect. The other variables have the same definitions as in table 6. In June of each year from 1995 to 2001, all stocks in our sample are equally divided into two groups (small and big) according to size (price times number of tradable shares). At the same time, independent to the size sorting, stocks are also ranked on the orthogonal floating ratios (residuals) that are calculated based on a regression of floating ratios on log market capitalization for all stocks and months. According to their floating ratio sorting, stocks are divided into three groups (high, medium, low) with high and low groups containing about $30 \%$ of stocks each. We then form six portfolios using equal weights from the intersection of the two size and three floating ratio groups. These portfolios are used to construct proxies for size (SMB) and the floating ratio (FR_HML). In particular, SMB is the difference between a simple average return of the three small stock portfolios (Small/Low, Small/Medium, and Small/High) and a simple average return of the three big stock portfolios (Big/Low, Big/Medium, and Big/High). The FR_HML is the difference between a simple average return of the two high ratio portfolios (Small/High, and Big/High) and a simple average return of two low ratio portfolios (Small/Low and $\mathrm{Big} / \mathrm{Low})$.

\begin{tabular}{|c|c|c|c|c|c|c|c|c|c|c|}
\hline \multicolumn{11}{|c|}{$\mathbf{R}_{\mathrm{t}}-\mathbf{R}_{\mathrm{f}, \mathrm{t}}=\alpha+s \mathrm{SMB}_{\mathrm{t}}+h \mathrm{FR} \_\mathrm{HML}_{\mathrm{t}}+\mathrm{e}_{\mathrm{t}}$} \\
\hline & Low & & & & High & Low & & & & High \\
\hline \multirow{5}{*}{ Small } & \multicolumn{5}{|c|}{$\alpha$} & \multicolumn{5}{|c|}{$\mathbf{t}(\alpha)$} \\
\hline & 0.011 & 0.020 & 0.021 & 0.030 & 0.032 & 1.20 & 1.91 & 2.02 & 2.75 & 2.83 \\
\hline & 0.016 & 0.034 & 0.020 & 0.023 & 0.028 & 1.69 & 1.88 & 1.75 & 2.16 & 2.43 \\
\hline & 0.015 & 0.016 & 0.019 & 0.018 & 0.020 & 1.49 & 1.61 & 1.78 & 1.70 & 1.66 \\
\hline & 0.021 & 0.022 & 0.018 & 0.020 & 0.019 & 1.93 & 2.12 & 1.65 & 1.69 & 1.78 \\
\hline \multirow[t]{2}{*}{ Big } & 0.019 & 0.038 & 0.023 & 0.015 & 0.017 & 1.78 & 3.16 & 2.11 & 1.38 & 1.49 \\
\hline & \multicolumn{5}{|c|}{$\mathbf{s}$} & \multicolumn{5}{|c|}{$t(s)$} \\
\hline \multirow[t]{4}{*}{ Small } & 0.68 & 0.82 & 0.77 & 0.54 & 0.70 & 3.03 & 3.19 & 2.99 & 2.04 & 2.50 \\
\hline & 0.35 & 1.53 & 0.61 & 0.52 & 0.68 & 1.54 & 3.42 & 2.11 & 1.96 & 2.41 \\
\hline & 0.24 & 0.15 & 0.25 & 0.42 & 0.22 & 0.94 & 0.59 & 0.96 & 1.55 & 0.73 \\
\hline & 0.05 & $-\mathbf{0 . 1 7}$ & 0.08 & -0.31 & -0.14 & 0.17 & -0.64 & 0.30 & -1.07 & -0.54 \\
\hline \multirow[t]{2}{*}{ Big } & -0.79 & -0.85 & -0.49 & -0.43 & -0.36 & -2.97 & -2.86 & -1.87 & -1.56 & -1.24 \\
\hline & \multicolumn{5}{|c|}{$\mathbf{h}$} & \multicolumn{5}{|c|}{$\mathbf{t}(\mathbf{h})$} \\
\hline \multirow[t]{4}{*}{ Small } & 0.14 & 0.70 & 0.97 & 0.61 & 1.33 & 0.63 & 2.74 & 3.79 & 2.31 & 4.77 \\
\hline & 0.55 & -0.43 & 1.05 & 0.96 & 1.21 & 2.40 & -0.97 & 3.63 & 3.67 & 4.33 \\
\hline & $\mathbf{0 . 5 7}$ & 0.63 & 1.13 & 1.03 & 1.68 & 2.25 & 2.53 & 4.30 & 3.87 & 5.51 \\
\hline & 0.04 & 0.80 & 0.91 & 1.09 & 1.44 & 0.16 & 3.05 & 3.46 & 3.73 & 5.49 \\
\hline \multirow[t]{2}{*}{ Big } & 0.63 & $\mathbf{0 . 0 3}$ & 0.71 & 0.84 & 1.49 & 2.40 & 0.10 & 2.69 & 3.03 & 5.15 \\
\hline & \multicolumn{5}{|c|}{$\mathbf{R}^{2}$} & & & & & \\
\hline \multirow[t]{4}{*}{ Small } & 0.13 & 0.27 & 0.33 & 0.16 & 0.37 & & & & & \\
\hline & 0.13 & 0.11 & 0.26 & 0.25 & 0.33 & & & & & \\
\hline & 0.09 & 0.09 & 0.24 & 0.24 & 0.33 & & & & & \\
\hline & -0.02 & 0.09 & 0.15 & 0.13 & 0.28 & & & & & \\
\hline Big & 0.09 & 0.09 & 0.06 & 0.08 & 0.24 & & & & & \\
\hline
\end{tabular}


Table 8. Time Series Regressions for the 25 Portfolios from July 1995 to June 2002 Using Proxies for the Market, the Size and the Floating Ratio

This table reports results (coefficients and t values) from the regressing each portfolio's excess returns on three factors including the excess market return, the SMB, and the FR_HML, i.e. $\mathrm{R}_{\mathrm{t}}-\mathrm{R}_{\mathrm{f}, \mathrm{t}}=\alpha+\beta\left(\mathrm{R}_{\mathrm{m}, \mathrm{t}}-\mathrm{R}_{\mathrm{f}, \mathrm{t}}\right)+s \mathrm{SMB}_{\mathrm{t}}+$ $h$ FR_HML ${ }_{t}+e_{t}$, over the sample period from July 1995 to June 2002. Variable definitions can be found in table 6 and $\overline{7}$.

\begin{tabular}{|c|c|c|c|c|c|c|c|c|c|c|}
\hline & Low & & & & High & Low & & & & High \\
\hline \multirow{5}{*}{ Sma11 } & \multicolumn{5}{|c|}{$\alpha$} & \multicolumn{5}{|c|}{$t(\alpha)$} \\
\hline & -0.006 & -0.001 & -0.002 & 0.007 & 0.007 & -1.20 & -0.21 & -0.42 & 1.47 & 1.96 \\
\hline & -0.004 & -0.003 & -0.005 & 0.000 & 0.002 & -1.28 & -0.28 & -1.48 & -0.14 & 0.65 \\
\hline & $-\mathbf{0 . 0 0 7}$ & -0.006 & -0.005 & -0.006 & -0.006 & -1.94 & -1.59 & -1.40 & -1.76 & -1.03 \\
\hline & -0.003 & -0.001 & -0.006 & -0.007 & -0.005 & -1.10 & -0.52 & -1.64 & -2.05 & -1.33 \\
\hline \multirow{2}{*}{ Big } & -0.005 & 0.011 & -0.001 & -0.009 & -0.009 & -1.57 & 3.11 & -0.26 & -2.55 & -2.50 \\
\hline & \multicolumn{5}{|c|}{$\boldsymbol{\beta}$} & \multicolumn{5}{|c|}{$\mathbf{t}(\boldsymbol{\beta})$} \\
\hline \multirow[t]{4}{*}{ Small } & 0.70 & 0.85 & 0.91 & 0.93 & 1.02 & 12.92 & 15.58 & 23.59 & 20.27 & 28.65 \\
\hline & 0.81 & 1.48 & 1.05 & 0.95 & 1.03 & 23.05 & 15.96 & 28.18 & 26.67 & 32.84 \\
\hline & 0.91 & 0.89 & 0.96 & 0.98 & 1.05 & 24.52 & 24.26 & 28.18 & 29.76 & 19.36 \\
\hline & 1.00 & 0.97 & 0.95 & 1.08 & 0.95 & 31.88 & 34.53 & 26.26 & 33.08 & 27.13 \\
\hline \multirow[t]{2}{*}{ Big } & 0.97 & 1.09 & 0.95 & 1.00 & 1.06 & 30.61 & 29.82 & 25.84 & 27.23 & 30.05 \\
\hline & \multicolumn{5}{|c|}{$\mathbf{s}$} & \multicolumn{5}{|c|}{$\mathbf{t}(\mathbf{s})$} \\
\hline \multirow{4}{*}{ Small } & 0.77 & 0.94 & 0.89 & 0.67 & 0.83 & 5.97 & 7.20 & 9.62 & 6.11 & 9.85 \\
\hline & 0.46 & 1.73 & 0.75 & 0.64 & 0.81 & 5.48 & 7.79 & 8.45 & 7.56 & 10.88 \\
\hline & 0.36 & 0.26 & 0.38 & 0.54 & 0.36 & 4.07 & 3.03 & 4.68 & 6.96 & 2.79 \\
\hline & 0.18 & -0.04 & 0.20 & $-\mathbf{0 . 1 7}$ & -0.02 & 2.39 & -0.61 & 2.36 & -2.22 & -0.20 \\
\hline \multirow[t]{2}{*}{ Big } & -0.66 & -0.71 & $-\mathbf{0 . 3 7}$ & -0.30 & -0.22 & -8.76 & -8.19 & -4.22 & -3.44 & -2.64 \\
\hline & \multicolumn{5}{|c|}{$\mathbf{h}$} & \multicolumn{5}{|c|}{$\mathbf{t}(\mathbf{h})$} \\
\hline \multirow[t]{4}{*}{ Small } & -0.39 & 0.06 & 0.27 & -0.09 & 0.56 & -2.91 & 0.41 & 2.83 & -0.83 & 6.28 \\
\hline & -0.07 & -1.56 & 0.25 & 0.24 & 0.43 & -0.81 & -6.75 & 2.68 & 2.70 & 5.44 \\
\hline & -0.12 & -0.05 & 0.40 & 0.29 & 0.87 & -1.33 & -0.54 & 4.73 & 3.53 & 6.45 \\
\hline & -0.72 & 0.06 & 0.19 & 0.27 & 0.72 & -9.21 & 0.86 & 2.05 & 3.32 & 8.20 \\
\hline \multirow[t]{2}{*}{ Big } & -0.11 & -0.80 & -0.02 & 0.07 & 0.68 & -1.34 & -8.80 & -0.17 & 0.80 & 7.77 \\
\hline & \multicolumn{5}{|c|}{$\mathbf{R}^{2}$} & & & & & \\
\hline \multirow[t]{4}{*}{ Small } & 0.71 & 0.81 & 0.91 & 0.86 & 0.94 & & & & & \\
\hline & 0.88 & 0.78 & 0.93 & 0.92 & 0.95 & & & & & \\
\hline & 0.89 & 0.89 & 0.93 & 0.94 & 0.88 & & & & & \\
\hline & 0.92 & 0.94 & 0.91 & 0.94 & 0.93 & & & & & \\
\hline Big & 0.93 & 0.92 & 0.90 & 0.91 & 0.94 & & & & & \\
\hline
\end{tabular}

